\title{
Surface modification of silica-coated on the magnetic nanoparticles with covalently immobilized between imidazolium cation and silane groups for potential application as a green catalyst
}

\begin{abstract}
The objective of this work is producing a magnetic green Nano catalyst for production of coumarins derivatives by solvent-free protocol. In this research, surface modification silica-coated on the magnetic nanoparticles with covalently immobilized between the imidazolium cation and the 3-chloropropyltrimethoxysilane linker groups. The structure of the catalyst was characterized by XRD, FT-IR, TGA, VSM and SEM. The $\mathrm{Fe}_{3} \mathrm{O}_{4} @ \mathrm{SiO}_{2}$-IM nanoparticle has been used to be an efficient green Nano catalyst for produce of coumarin derivatives by solvent-free protocol. This catalyst is a suitable, owing to its non-toxicity, low-cost and eco-friendly properties. Also, this catalyst can be recovered simply using an external magnetic field. The catalyst was reused several times without losing its catalytic activity.
\end{abstract}

Keywords: magnetic nanoparticles, ionic liquid, imidazole, coumarin, solvent-free
Volume 2 Issue I - 2018

\author{
Rasoul Shahbazi, ${ }^{1,2}$ Mirzaagha Babazadeh,' \\ Elham Afzali² \\ 'Department of Chemistry, Tabriz Branch, Islamic Azad \\ University, Tabriz, Iran \\ ${ }^{2}$ Department of Chemistry, Science and Research Branch, \\ Islamic Azad University, Iran
}

\begin{abstract}
Correspondence: Rasoul Shahbazi, Department of Chemistry, Faculty of Science, Islamic Azad University Research and Science Branch Tehran, Iran, Tel +989|46171640,

Email Shahbazi.rasoul@yahoo.com
\end{abstract}

Received: December 05, 2017 | Published: January 23, 2018
Abbreviations: ILs, ionic liquids; CMNPs, citrate-coated magnetite nanoparticles; TEOS, tetraethoxyorthosilicate; CPTMS, 3-cloropropyltrimethoxysilane; IM, imidazole; XRD, x-ray diffraction; FT-IR, fourier-transform infrared spectroscopy; TGA, thermal gravimetric analysis; VSM, vibrating-sample magnetometer; SEM, scanning electron microscope; TLC, thin-layer chromatography

\section{Introduction}

In the past decade, ionic liquids (ILs) have attracted increasing attention in organic synthesis and catalysis. The favorable characteristics, such as low vapor pressure, high thermal stability, and peculiar ion environment, make ILs "green" alternatives to replacing traditional organic solvents. ${ }^{1}$ Though ionic liquids possessed such promising advantages, their widespread practical application was still hampered by several drawbacks:

i. High viscosity, which resulted in only a minor part of ionic liquids took part in the catalyzed reaction

ii. Homogeneous reaction, which was difficult for product separation and catalyst recovery, and

iii. Consequently high cost for the use of relatively large amounts of ionic liquids. ${ }^{2,3}$

Therefore, in order to resolve these issues mentioned earlier, grafting or immobilizing became general concepts applied to heterogenize ILs that is recognized as a green approach in catalytic applications. ${ }^{4,5}$ Silica is usually used as an ionic liquid carrier because of its ease of availability, non-toxicity, low cost and high surface area. ${ }^{6-8}$ Furthermore, compared with pure ionic liquids, these immobilized ionic liquids show additional advantages, such as significantly decrease of the amounts of ionic liquid, the facilitation of catalyst separation from reaction system and more rapid mass transfer, lower contamination of product, and the ability of using it in gas phase reactions..$^{9-11}$

Executing reactions under solvent-free conditions is very important strategy in organic synthesis that appreciably reduces the waste production and precludes post-synthesis steps such as product isolation and solvent recycling. Moreover, in recent years ionic liquids have been successfully employed as solvents with catalytic activity for a variety of reactions but their use as catalyst under solvent free conditions need to be given more attention. ${ }^{12-14}$

On the other hand, utilizing magnetic nanoparticles, catalyst separation from reaction system is facilitated. ${ }^{14}$ Coumarin derivatives are an important class of natural products with interesting therapeutic and biological properties. These compounds find application in agrochemicals, fragrances, agrochemicals, pharmaceuticals, insecticides and also are extensively used in anticancer for preparation of optical brighteners and laser dyes, anticoagulant, anti-HIV, antibacterial. ${ }^{15-25}$ These reactions are usually catalyzed by different Bronsted and Lewis acids in homogeneous and heterogeneous pathway. ${ }^{14,26-33}$ This research indicated that $\mathrm{Fe}_{3} \mathrm{O}_{4} @ \mathrm{SiO}_{2}$-IM organicinorganic hybrid nanostructure can be used as an appropriate heterogeneous acidic catalyst for solvent-free protocol synthesis of coumarin by condensation of phenolic compounds with methyl acetoacetate. Eventually, in the context of our work this catalyst is desirable replacement, owing to its low-cost non-toxicity, and ecofriendly properties.

\section{Experimental}

\section{Materials and methods}

Iron (III) chloride hexahydrate $\left(\mathrm{FeCl}_{3} \cdot 6 \mathrm{H}_{2} \mathrm{O}\right)$, iron (II) chloride tetrahydrate $\left(\mathrm{FeCl}_{2} \cdot 4 \mathrm{H}_{2} \mathrm{O}\right)$, ammonium hydroxide solution $\left(\mathrm{NH}_{3} \cdot \mathrm{H}_{2} \mathrm{O}\right.$, $25 \%$ ), tetraethylorthosilicate (TEOS), 3-chloropropyltrimethoxysilane 
(CPTMS), Imidazole, methyl acetoacetate, phenolic compounds and all chemical solvents were obtained from the Sigma or Merck companies.

\section{Synthesis of magnetite nanoparticles}

Magnetic nanoparticles were synthesized by chemical coprecipitation method under alkaline condition. ${ }^{34} 3.18 \mathrm{gr}$ of $\mathrm{FeCl}_{3} \cdot 6 \mathrm{H}_{2} 0$ and $1.85 \mathrm{gr}$ of $\mathrm{FeCl}_{2} \cdot 4 \mathrm{H}_{2} \mathrm{O}$ were dissolved in $50 \mathrm{ml}$ of water in a round bottom flask and under $\mathrm{N}_{2}$ atmosphere with vigorous stirring. The mixed solution was stirred under $\mathrm{N}_{2}$ at $80^{\circ} \mathrm{C}$ for $2 \mathrm{~h}$. $10 \mathrm{ml}$ of $\mathrm{NH}_{4} \mathrm{OH}$ was added into the reaction mixture drop wise, stirred under $\mathrm{N}_{2}$ for another $2 \mathrm{~h}$ and then cooled to room temperature. The precipitated black powders were collected and washed for several times with deionized water and EtOH. Lastly, magnetite nanoparticles were dried under vacuum at $8^{\circ} \mathrm{C}$ (Figure 1 ).

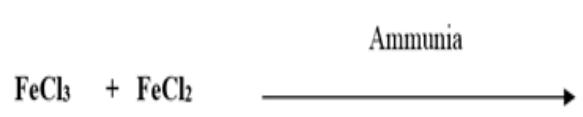

Figure I Synthesis of magnetite nanoparticles.

\section{Synthesis of citrate-coated magnetite nanoparticles}

To obtain the well-dispersed magnetite nanoparticles, the prepared magnetic nanoparticles were added to $30 \mathrm{ml}$ of $0.1 \mathrm{M}$ citric acid with ultrasonic treatment for $30 \mathrm{~min}$ and the reaction was maintained for $12 \mathrm{~h}$ at room temperature, and the final product was washed several times with water. The obtained citrate-coated magnetite nanoparticles were separated with external magnetic field ${ }^{35}$ (Figure 2).
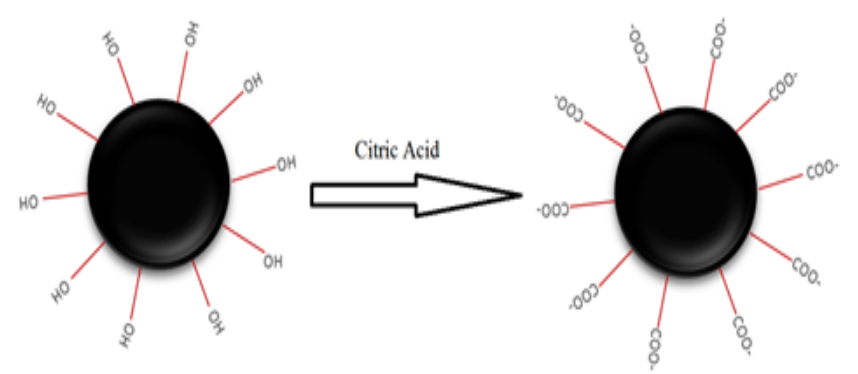

Figure 2 Synthesis of citrate-coated magnetite nanoparticles.

\section{Coating of nanoparticles with silica layer}

The obtained CMNPs above were diluted with $20 \mathrm{ml} \mathrm{EtOH}$ and $2 \mathrm{ml}$ deionized water and the mixture was sonicated for $30 \mathrm{~min}$. Under continuous stirring, $5 \mathrm{ml} \mathrm{NH} \mathrm{H}_{4} \mathrm{OH}$ and $2 \mathrm{ml}$ TEOS were consecutively added to the reaction mixture. The resulting mixture under $\mathrm{N}_{2}$ atmosphere was stirred for $12 \mathrm{~h}$ at room temperature and then the coreshell nanocomposites were again isolated with a magnet and washed several times with EtOH and water (Figure 3).

\section{Modification of nanoparticles surface}

The obtained synthesized nanoparticles were dispersed in $100 \mathrm{ml}$ of $\mathrm{EtOH}$ and then $2 \mathrm{ml}$ of toluene was added to the solution and the resulting solution was sonicated for $30 \mathrm{~min}$, then $2 \mathrm{ml}$ of CPTMS was added drop wise to the solution. The mixture was stirred for 2 days under nitrogen atmosphere. The modified nanoparticles were again isolated with a magnet and at that time the precipitated particles were washed with $\mathrm{MeOH}$ for several times (Figure 4).

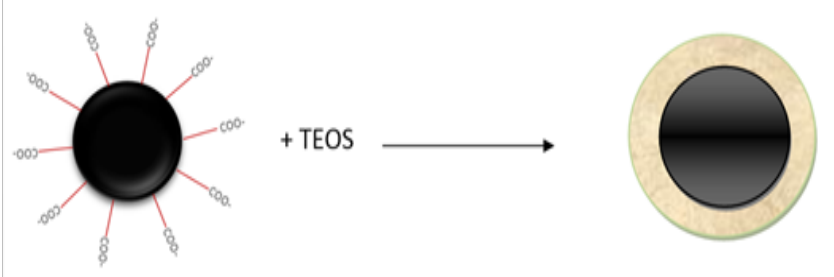

Figure 3 Coating of nanoparticles with silica layer.

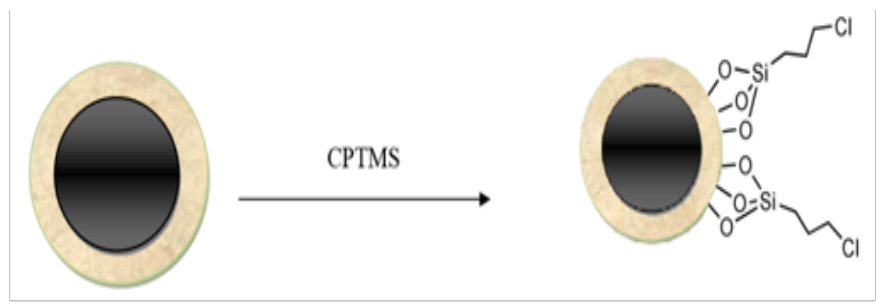

Figure 4 Modification of nanoparticles surface with 3-cloropropyltrimethoxysilane.

\section{Synthesis of $\mathrm{Fe}_{3} \mathrm{O}_{4} @ \mathrm{SiO}_{2}-\mathrm{IM}$}

$1.2 \mathrm{gr}$ of Imidazole was added to $10 \mathrm{ml}$ of $\mathrm{CHCl}_{3}$, and then the modified nanoparticles were added to the resulting solution. The suspension was vigorous stirred and refluxed for two days and then the brown solid washed by $\mathrm{CHCl}_{3}$ and was dried (Figure 5).

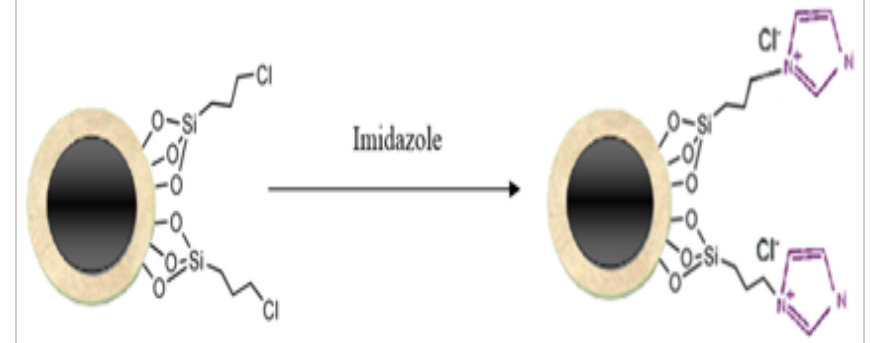

Figure 5 Synthesis of $\mathrm{Fe}_{3} \mathrm{O}_{4} @ \mathrm{SiO}_{2}-\mathrm{IM}$.

\section{Catalyst characterization}

SEM images were obtained using a KYKY EM-3200 instrument. FT-IR spectra of the materials were recorded over the range of $400-4000 \mathrm{~cm}^{-1}$ region by using a Bruker Tensor 27 series FT-IR spectrometer. TGA was recorded in the range of 25-800 centigrade and XRD on a Siemens $\mathrm{D}=5000 \mathrm{X}$-ray Diffractometer, using $\mathrm{CuK} \alpha$ radiation $\left(\lambda=1.5418 \mathrm{~A}^{\circ}\right)$ at $30 \mathrm{kV}$ and $30 \mathrm{~mA}$.

\section{Typical procedure for the synthesis of coumarin deri- vatives}

The phenolic compound ( $1 \mathrm{mmol})$, methyl acetoacetate $(1 \mathrm{mmol})$ and synthesized nanocatalyst $\left(\mathrm{Fe}_{3} \mathrm{O}_{4} @ \mathrm{SiO}_{2}-\mathrm{IM}\right)(0.15 \mathrm{gr})$ were placed in a glass flask equipped with a magnetic stirrer at $80^{\circ} \mathrm{C}$ for suitable times. The reaction was monitored by TLC, and after completion of reaction, the reaction mixture was diluted with cold water and stirred for $15 \mathrm{~min}$. EtOH was added to the reaction mixture and sample were separated by external magnet then the product was purified by recrystallization from EtOH (Figure 6). 


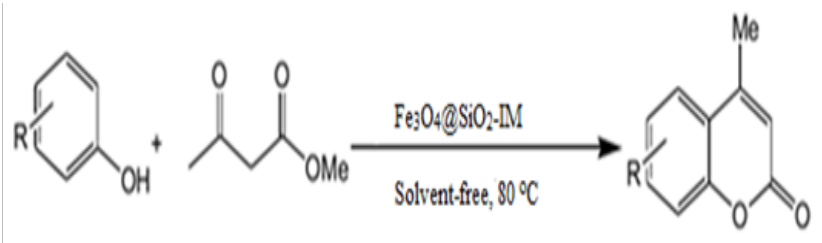

Figure 6 Typical procedure for the synthesis of coumarin derivatives.

\section{Results and discussion}

\section{Preparation and characterization of the catalyst}

The magnetite nanoparticles were simply synthesized via the co-precipitation method. Citric acid was used as a coating agent and completed stable colloidal dispersion. ${ }^{35}$ The choice of citric acid over other frequently offered coating agents is to control the prevent aggregation of magnetite nanoparticles, coating the magnetite nanoparticles with the silica would be a good solution. Likewise, the silica hydroxyl groups were modified by silene groups with covalently bond. In conclusion, imidazole was immobilized on the core-shell nanostructure with covalently bond between Silane groups and imidazole under the $\mathrm{S}_{\mathrm{N} 2}$ reaction.

Figure 7 shows the XRD powder diffraction pattern of $\mathrm{Fe}_{3} \mathrm{O}_{4} @$ $\mathrm{SiO}_{2}$-IM. All of the observed diffraction peaks are indexed by the cubic structure of $\mathrm{Fe}_{3} \mathrm{O}_{4}$ (PDF: 00-011-0614). As can be seen, the XRD pattern of $\mathrm{Fe}_{3} \mathrm{O}_{4} @ \mathrm{SiO}_{2}-\mathrm{IM}$ was in agreement with that of the standard magnetite structure indicated that these particles have phase stability and the structural integrity was preserved. A broad diffraction peak near $2 \theta=10-30^{\circ}$ is observed in the $\mathrm{Fe}_{3} \mathrm{O}_{4} @ \mathrm{SiO}_{2}-\mathrm{IM}$ powder. This may be attributed to the amorphous silica.

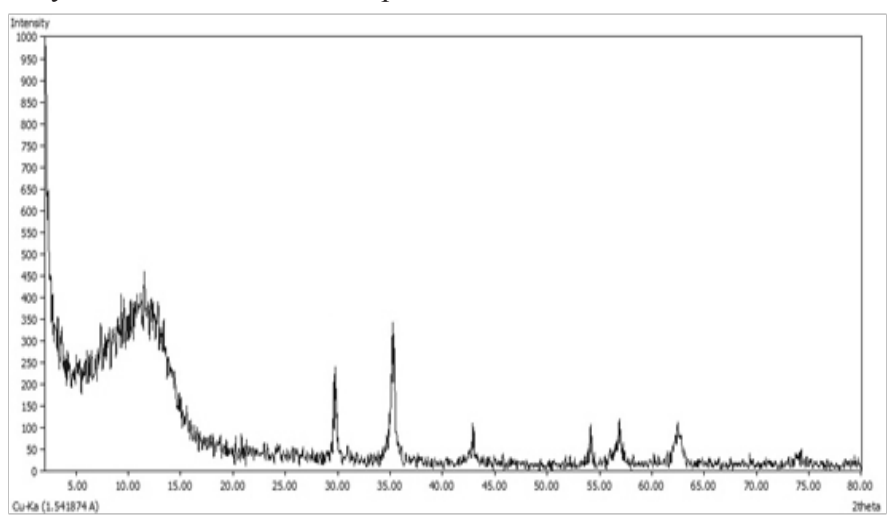

Figure 7 XRD of $\mathrm{Fe}_{3} \mathrm{O}_{4} @ \mathrm{SiO}_{2}-\mathrm{IM}$.

The Fourier transform infrared (FT-IR) spectra of (a) $\mathrm{Fe}_{3} \mathrm{O}_{4}$ and (b) $\mathrm{Fe}_{3} \mathrm{O}_{4} @ \mathrm{SiO}_{2}-\mathrm{IM}$ are shown in Figure 8A. The FT-IR spectrum of $\mathrm{Fe}_{3} \mathrm{O}_{4}$ nanoparticles (Figure 2A) the absorption bands around $3425 \mathrm{~cm}^{-1}$ is attributed to the stretching vibrations of $-\mathrm{OH}$ and the peak at $1629 \mathrm{~cm}^{-1}$ is assigned to the -OH bending. 455 and $585 \mathrm{~cm}^{-1}$ is attributed to the $\mathrm{M}-\mathrm{O}$ bond vibration of magnetite nanoparticles.

The IR spectrum represented in the Figure 8B. Reveals the characteristic bonds of ILs modified on the silica-coated nanoparticles. The broad high-intensity bands at 1084 and $748 \mathrm{~cm}^{-1}$ are assigned to the $\mathrm{Si}-\mathrm{O}-\mathrm{Si}$ asymmetric and symmetric vibration, owing to the asymmetric stretching bonds of Si-O-Si in silica shell. The band at $1629 \mathrm{~cm}^{-1}$ corresponds to the bending vibrations of Si-OH. ${ }^{36}$ There are two characteristic bonds include C-H stretching 3128 and $2948 \mathrm{~cm}^{-1}$ and bending bonds at, 1531 and $1398 \mathrm{~cm}^{-1}$ of the $\mathrm{C}=\mathrm{N}$ and $\mathrm{C}=\mathrm{C}$ in IM rings.

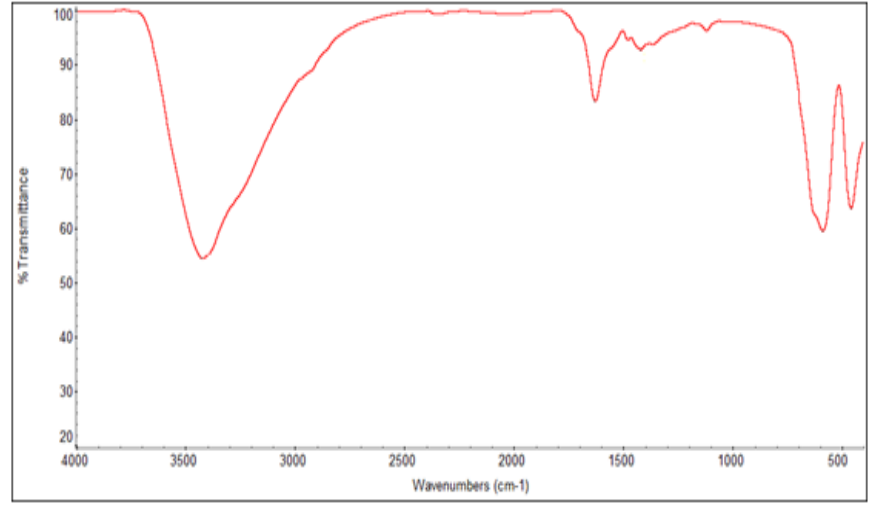

Figure 8A FTIR of magnetite nanoparticles.

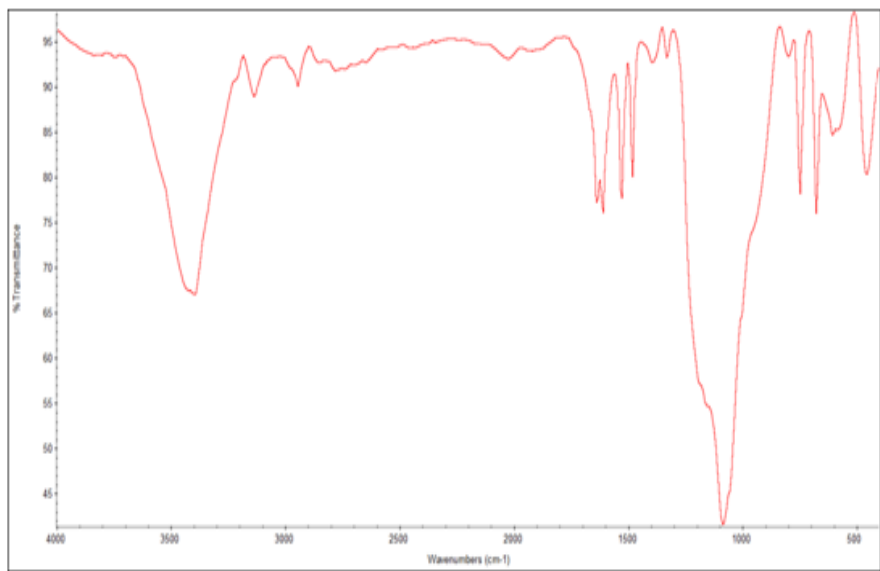

Figure 8B FTIR of $\mathrm{Fe}_{3} \mathrm{O}_{4} @ \mathrm{SiO}_{2}-\mathrm{IM}$ nanoparticles.

The morphological properties of magnetite nanoparticle and were studied using SEM. As shown in Figure 9A, show the $\mathrm{Fe}_{3} \mathrm{O}_{4}$ nanoparticles with uniform structures. Besides, as it is shown in Figure 3B, the $\mathrm{Fe}_{3} \mathrm{O}_{4} @ \mathrm{SiO}_{2}$-IM has sphere morphology, even after surface modification of silica-coated nanoparticles with IL groups (Figure 9B).

\section{Thermo gravimetric analysis of $\mathrm{Fe}_{3} \mathrm{O}_{4} @ \mathrm{SiO}_{2}-\mathrm{IM}$ nano- particles}

Test thermal stability of $\mathrm{Fe}_{3} \mathrm{O}_{4} @ \mathrm{SiO}_{2}-\mathrm{IM}$ nanoparticles, Thermo gravimetric analysis (TGA) between 25 and 800 centigrade in a nitrogen atmosphere were static. Analysis TGA, the $\mathrm{Fe}_{3} \mathrm{O}_{4} @ \mathrm{SiO}_{2}-\mathrm{IM}$ nanoparticles is a weight loss owing to water absorption below 160 centigrade. The other weight loss due to loss of organic groups was indicated between 185 and 384 (Figure 10).

\section{Vibrating sample magnetometer of $\mathrm{Fe}_{3} \mathrm{O}_{4} @ \mathrm{SiO}_{2}-\mathrm{IM}$ nanoparticles}

In the analysis of VSM, the magnetic properties of synthesized nanocatalysts $42 \mathrm{emu} / \mathrm{g}$, respectively (Figure 11).

\section{Catalytic activity of $\mathrm{Fe}_{3} \mathrm{O}_{4} @ \mathrm{SiO}_{2}-\mathrm{IM}$ nanoparticles for synthesis of coumarin derivatives}

The catalytic application of $\mathrm{Fe}_{3} \mathrm{O}_{4} @ \mathrm{SiO}_{2}$-IM nanoparticle was used as a suitable heterogeneous catalyst for solvent-free protocol 
synthesis of coumarin by condensation of phenolic compounds with methyl acetoacetate. To optimize the reaction conditions, phenol and methyl acetoacetate were selected as the model substrates to examine the effects of different solvents and molar ratios of the catalyst at different temperatures. The effect of different solvents on the course of reaction was studied (Table 1). From the results given in Table 1 , it was found that among various solvents tried, solvent-free was found to give optimum results in term of reaction time and yield. Consequently, the optimum conditions for the reaction are: $0.15 \mathrm{~g}$ of $\mathrm{Fe}_{3} \mathrm{O}_{4} @ \mathrm{SiO}_{2}-\mathrm{IM}$ nanoparticle, $80^{\circ} \mathrm{C}$ was found to be the optimum reaction temperature and solvent-free protocol.

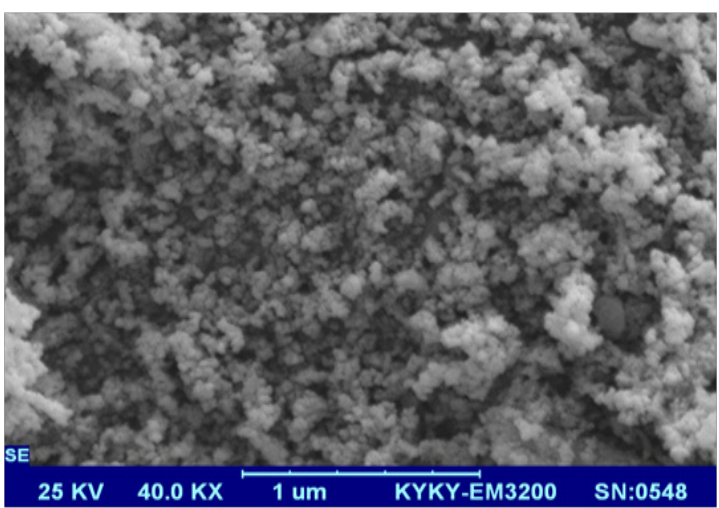

Figure 9A SEM of magnetite nanoparticles.

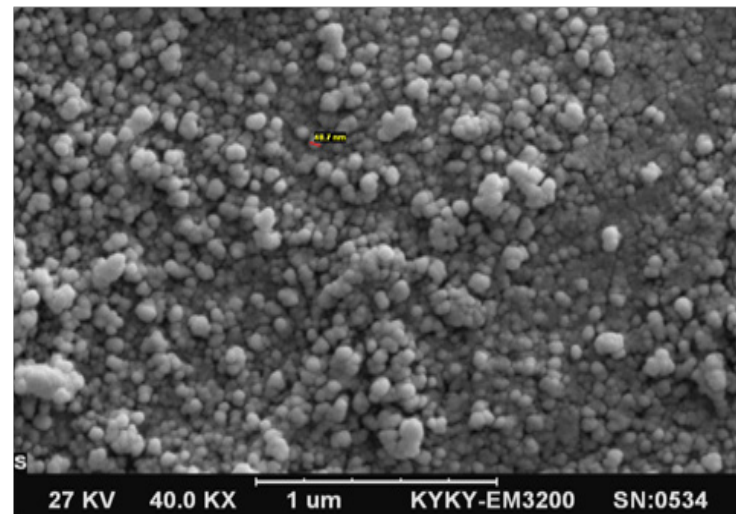

Figure 9B SEM of $\mathrm{Fe}_{3} \mathrm{O}_{4} @ \mathrm{SiO}_{2}-\mathrm{IM}$ nanoparticles.

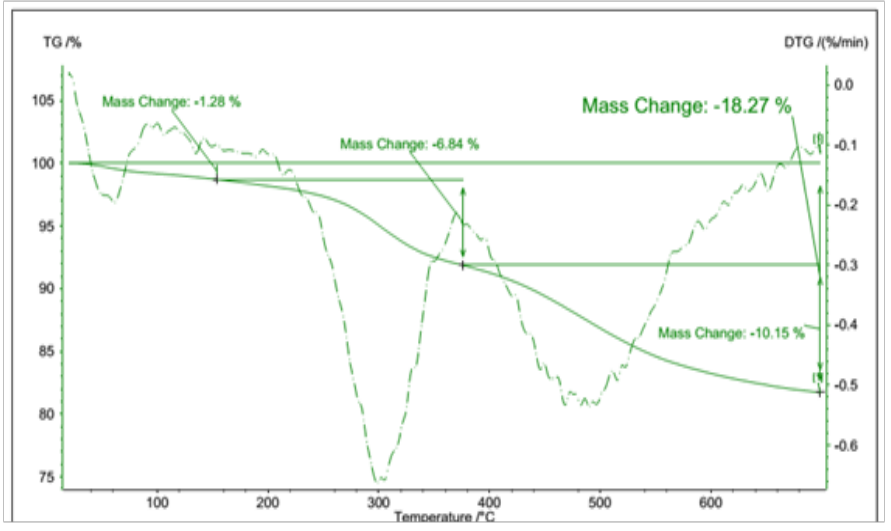

Figure $10 \mathrm{TGA}$ of $\mathrm{Fe}_{3} \mathrm{O}_{4} @ \mathrm{SiO}_{2}$-IM nanoparticles.

In order to generalize the scope of reaction, a variety of phenols was subjected for reaction with methyl acetoacetate under the solvent- free optimized reaction conditions, and the results are presented in Table 2. The spectral data and melting points are in good agreement with those reported in literature. The reactions went on well to afford products in good to high yields and short times. ${ }^{37}$

It was obvious, which the recycle of a heterogeneous system and the lifetime of the catalyst are highly better in terms of green chemistry. This research used the reused catalytic five times without any reduction in the chemical reaction. The competence of the catalytic activity after five times recycling illustrated in Figure 12.

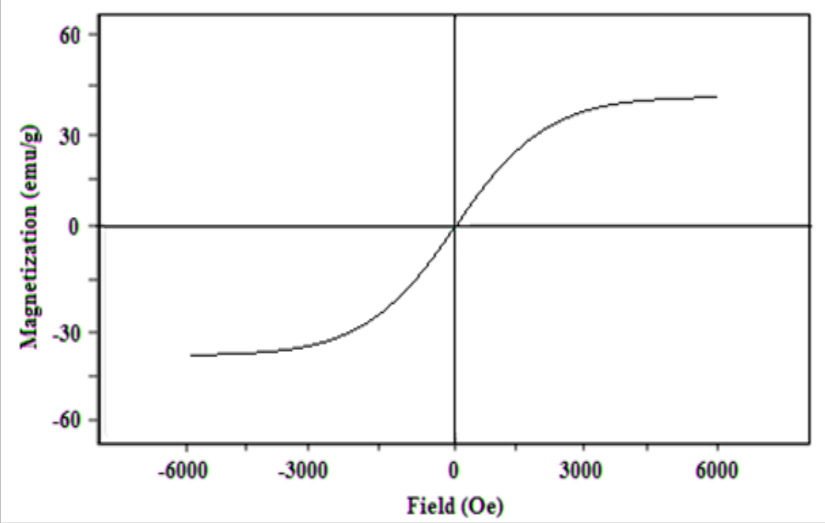

Figure II TGA of $\mathrm{Fe}_{3} \mathrm{O}_{4} @ \mathrm{SiO}_{2}-\mathrm{IM}$ nanoparticles.

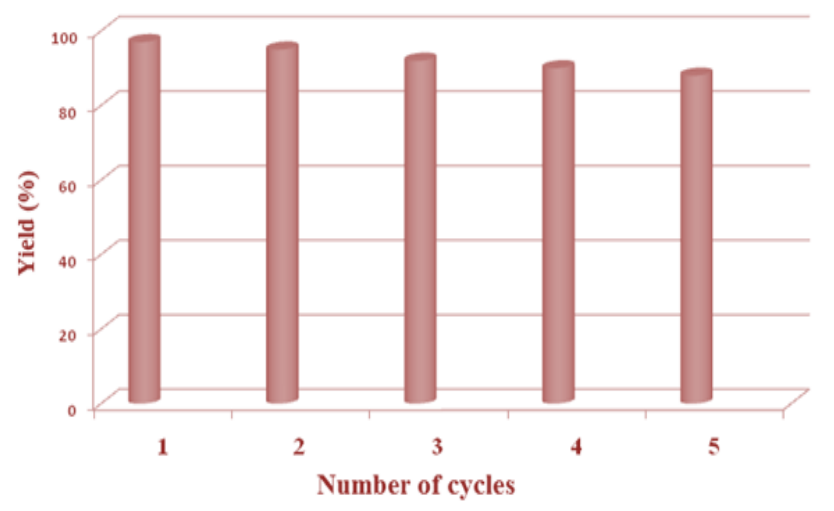

Figure 12 The $\mathrm{Fe}_{3} \mathrm{O} 4 @ \mathrm{SiO} 2-\mathrm{IM}$ nanoparticle recycled in the synthesis of coumarin derivatives.

\section{Selected spectral data of the products}

2a: 4-Methyl-2H-chromen-2-one: $\mathrm{Mp} .:$ 78-80 ${ }^{\circ} \mathrm{C}$; IR (KBr): 1702, $1638,1543,1450,1385,1085,928,852,755 \mathrm{~cm}^{-1} ;{ }^{1} \mathrm{H}-\mathrm{NMR}(400 \mathrm{MHz}$, DMSO-d6) $\delta$ (ppm) 7.8-6.63 (m, 4H), 6.12 (s, 1H), 2.32 (s, 3H).

2b: 7-Hydroxy-4-methyl-2H-chromen-2-one: Mp.: $184-187^{\circ} \mathrm{C}$; IR (KBr): 3163, 1690, 1590, 1382, 1275, 1233, 1059, 975, 850, 803, $750 \mathrm{~cm}^{-1}$; ${ }^{1} \mathrm{H}-\mathrm{NMR}(400 \mathrm{MHz}$, DMSO-d6) $\delta(\mathrm{ppm}) 10.53$ (br, $1 \mathrm{H})$, 7.61-7.53 (br, 1H), 6.81-6.66 (m, 2H), 6.14 (br, 3H), 2.36-2.31 (br, $3 \mathrm{H})$.

2c: 6-Hydroxy4-methyl-2H-chromen-2-one: $\mathrm{Mp}$.: 241-244 ${ }^{\circ} \mathrm{C}$; 1H-NMR (400MHz, DMSO-d6) $\delta(\mathrm{ppm}) 9.67(\mathrm{~s}, 1 \mathrm{H}), 7.27-7.20(\mathrm{br}$, $1 \mathrm{H}), 6.78-6.67$ (br, $2 \mathrm{H}), 6.09$ (s, 1H), $2.32(\mathrm{~s} .3 \mathrm{H})$

2g: 4,7-Dimethyl-2H-chromen-2-one: $\mathrm{Mp} .:$ 125-129 ${ }^{\circ} \mathrm{C}$; $\mathrm{IR}(\mathrm{KBr})$ : 3015, 2920, 1704, 1620, 1590, 1384, 1321, 1248, 1263, 1144, 1070, 954, 879, 710, 580 $\mathrm{cm}^{-1} ;{ }^{1} \mathrm{H}-\mathrm{NMR}(400 \mathrm{MHz}$, DMSO-d6) $\delta(\mathrm{ppm})$ 
$10.51(\mathrm{~s}, 1 \mathrm{H}), 10.29(\mathrm{~s}, 1 \mathrm{H}), 6.23(\mathrm{br}, 1 \mathrm{H}), 6.14(\mathrm{br}, 1 \mathrm{H}), 5.82(\mathrm{~s}, 1 \mathrm{H})$, $2,46(\mathrm{~s}, 3 \mathrm{H})$

2i: 7-Methoxy-4-methyl-2H-chromen-2-one: $\mathrm{Mp} .: 157-160^{\circ} \mathrm{C}$; IR (KBr): 3066, 2924, 1719, 1616, 1384, 1275, 1219, 1157, 960, 840, $710 \mathrm{~cm}^{-1}$; ${ }^{1} \mathrm{H}-\mathrm{NMR}$ (400MHz, DMSO-d6) $\delta$ (ppm) 7.68-7.65 (br, $\left.1 \mathrm{H}\right)$, 6.96-6.93 (br, 2H), 6.19 (s, 1H), 3.84 (s, 3H), 2.37 (s, 3H).

Table I Optimization condition for synthesis of coumarin derivatives by $\mathrm{Fe}_{3} \mathrm{O}_{4} @ \mathrm{SiO}_{2}-\mathrm{IM}$

\begin{tabular}{lllll}
\hline Entry & Solvent & Temperature & Time & Yield \% \\
\hline I & Dichloromethane & r.t. & $4 \mathrm{~h}$ & 5 \\
2 & Toluene & r.t. & $4 \mathrm{~h}$ & 15 \\
3 & Toluene & Reflux & $4 \mathrm{~h}$ & 40 \\
4 & Acetonitrile & r.t. & $4 \mathrm{~h}$ & 50 \\
5 & Acetonitrile & Reflux & $4 \mathrm{~h}$ & 30 \\
6 & Water & r.t. & $4 \mathrm{~h}$ & 50 \\
7 & Ethanol & r.t. & $4 \mathrm{~h}$ & 70 \\
8 & Solvent-free & $80^{\circ} \mathrm{C}$ & $15 \mathrm{~min}$ & 97 \\
\hline
\end{tabular}

Table 2 Synthesis of coumarin derivatives catalyzed by $\mathrm{Fe}_{3} \mathrm{O}_{4} @ \mathrm{SiO}_{2}-\mathrm{IM}$

\begin{tabular}{|c|c|c|c|c|c|}
\hline Entry & Phenol & Time (min) & Product & Melting point & Yield (\%) \\
\hline & & & & & \\
\hline I & & 15 & $2 a$ & $77-81$ & 97 \\
\hline 2 & & 20 & $2 b$ & $182-185$ & 94 \\
\hline 3 & & 25 & $2 c$ & $24 \mid-243$ & 92 \\
\hline & & & & & \\
\hline 4 & & 15 & $2 d$ & $162-165$ & 92 \\
\hline 5 & & 20 & $2 e$ & $247-249$ & 95 \\
\hline
\end{tabular}

Citation: Shahbazi R, Babazadeh M,Afzali E. Surface modification of silica-coated on the magnetic nanoparticles with covalently immobilized between imidazolium cation and silane groups for potential application as a green catalyst. MOJ Biorg Org Chem. 20 I8;2(I):I I-I7. DOI: I0.I5406/mojboc.20I8.02.00048 
Table Continued.

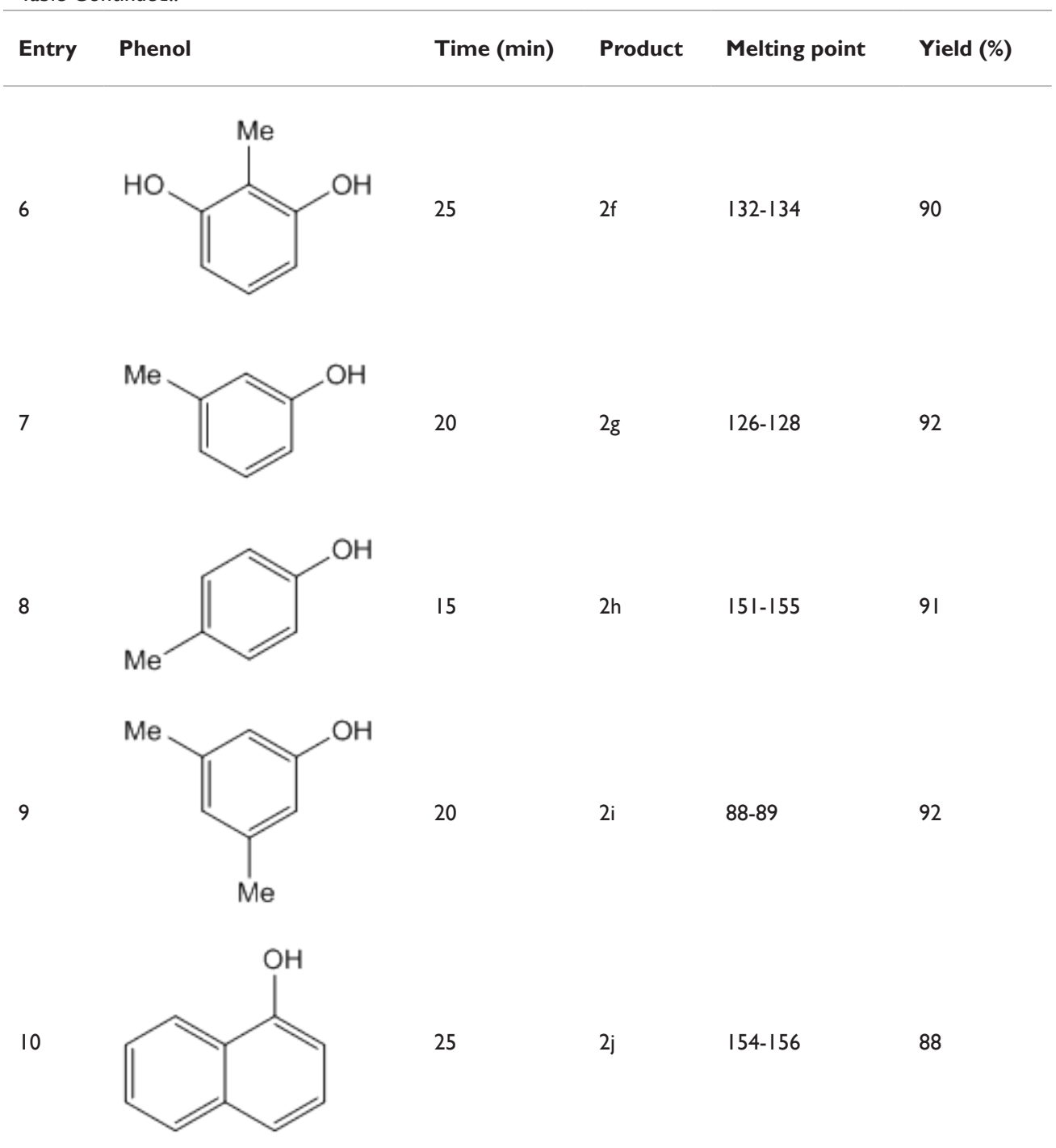

\section{Conclusion}

In this study, surface of silica-coated magnetite nanoparticles has been modified with covalently immobilized between the imidazole and the silane groups. Synthesized green nanocatalyst characterized by VSM, GTA, XRD, FTIR and SEM. The research found that $\mathrm{Fe}_{3} \mathrm{O}_{4} @$ $\mathrm{SiO}_{2}$-IM nanoparticle is an appropriate magnetic green nanocatalyst with a great stability for synthesis of coumarin derivatives under the solvent-free conditions. This catalyst also was found to be very stable after five times reusability. This resulted in an excellent recovery and efficient reuse of the catalyst. The magnetic nanocatalyst could also be readily separated from reaction systems by external magnetic field. easy preparation, hydrophobicity, Mild reaction conditions, High thermal stability, reusability of the catalyst and high activity make the present protocol a green alternative.

\section{Acknowledgements}

None.

\section{Conflict of interest}

The author declares no conflict of interest.

\section{References}

1. Gu Y, Li G. Ionic Liquids-Based Catalysis with Solids: State of the Art. Adv Synth Catal. 2009;351(6):817-847.

2. Sahoo S, Kumar P, Lefebvre F, et al. Oxidative kinetic resolution of alcohols using chiral Mn-salen complex immobilized onto ionic liquid modified silica. Appl Catal A. 2009;354(1-2):17-25.

3. Zhu L, Liu Y, Chen J. Synthesis of N-Methylimidazolium Functionalized Strongly Basic Anion Exchange Resins for Adsorption of Cr(VI). Ind Eng Chem Res. 2009;48(7):3261-3267.

4. Jiang $\mathrm{N}$, Jin $\mathrm{H}$, Mo YH, et al. Direct immobilization of $\mathrm{ImCl}$ ionic liquid onto the platelet type SBA-15. Microporous and Mesoporous Materials. 2011;141(1-3):16-19.

5. Polshettiwar V, Molnar A. Silica-supported Pd catalysts for Heck coupling reactions. Tetrahedron. 2007;63(30):6949-6976.

6. Polshettiwar V, Varma RS. Green chemistry by nano-catalysis. Green Chem. 2010;12(5):743-754.

7. Polshettiwar V, Luque R, Fihri A, et al. Magnetically recoverable nanocatalysts. Chem Rev. 2011;111(5):3036-3075. 
8. Abolghasemi MM, Karimi B, Yousefi V. Periodic mesoporous organosilica with ionic liquid framework as a novel fiber coating for headspace solid-phase microextraction of polycyclic aromatic hydrocarbons. Anal Chim Acta. 2013;804:280-286.

9. Li JN, Wang LN, Qi T, et al. Different N-containing functional groups modified mesoporous adsorbents for $\mathrm{Cr}(\mathrm{VI})$ sequestration: Synthesis, characterization and comparison. Micropor Mesopor Mat. 2008;110(23):442-450

10. Sujandi, Prasetyanto EA, Han DS, et al. Immobilization of Co(III) using tethered cyclam ligand on SBA-15 mesoporous silica for aerial oxidation of ethylbenzene. Catal Today. 2009;141(3-4):374-377.

11. Li J, Qi T, Wang L, et al. Synthesis and characterization of imidazolefunctionalized SBA-15 as an adsorbent of hexavalent chromium. Mater Lett. 2007;61(14-15):3197-3200.

12. Johnson WB, Zeinali M, Shaffer KM, et al. Detection of organics using porphyrin embedded nanoporous organosilicas. Biosens Bioelectron. 2007;22(6):1154-1162.

13. Lakouraj MM, Bagheri N, Hasantabar V. Synthesis and application of nanocrystalline-cellulose-supported acid ionic liquid catalyst in Pechmann reaction. Inter J Carbo Chem. 2013;2013:8.

14. Sharma RK, Monga Y, Puri A, et al. Magnetite $\left(\mathrm{Fe}_{3} \mathrm{O}_{4}\right)$ silica based organic-inorganic hybrid copper (ii) nanocatalyst: a platform for aerobic N-alkylation of amines. Green chem. 2013;15(10):2800-2809.

15. O’Kennedy R, Thornes RD. Coumarins: biology, applications, and mode of action. USA: John Wiley \& Sons; 1997.

16. Snow O. Amphetamine Syntheses Overview \& Reference Guide for Professionals. USA: Thoth Press; 1998.

17. Sethna SM, Shah NM. The Chemistry of Coumarins. Chem Rev. $1945 ; 36(1): 1-62$.

18. Liang XT, Fang WS. Medicinal Chemistry of Bioactive Natural Products. In: Hoboken, editor. USA: Wiley-Interscience, A John Wiley \& Sons; 2006. 460 p.

19. Cavettos G, Nano GM, Palmisano G, et al. An asymmetric approach to coumarin anticoagulants via hetero-Diels-Alder cycloaddition. Tetra. 2001;12(5):707-709.

20. Shriner RL. Reformatsky Reaction. Organic Reactions. USA: John Wiley \& Sons; 1942.

21. Yavari I, Hekmat-Shoar R, Zonouzi A. A new and efficient route to 4 carboxymethylcoumarins mediated by vinyltriphenylphosphonium salt. Tetra Lett. 1998;39(16):2391-2392.

22. Shaabani A, Ghadari R, Rahmati A, et al. Coumarin synthesis via Knoevenagel condensation reaction in $1,1,3,3-\mathrm{N}, \mathrm{N}, \mathrm{N}^{\prime}, \mathrm{N}^{\prime}$-tetramethylguanidinium trifluoroacetate ionic liquid. J Iran Chem Soc. 2009;6(4):710714.
23. Jones G. The Knoevenagel Condensation. Org React. 1967;15:204-599.

24. Brufola G, Fringuelli F, Piermatti O, et al. Simple and Efficient OnePot Preparation of 3-Substituted Coumarins in Water. Heterocycles. 1996;43(6):1257-1266.

25. Johnson JR. Perkin Reaction and Related Reactions. Org React. 1942;1:210-265.

26. Bose DS, Rudradas AP, Babu MH. The indium(III) chloride-catalyzed von Pechmann reaction: a simple and effective procedure for the synthesis of 4-substituted coumarins. Tetra Lett. 2002;43(50):9195-9197.

27. Khandekar AC, Khadilkar BM. Pechmann Reaction in Chloroaluminate Ionic Liquid. Synlett. 2002;1:152-154.

28. Singh PR, Singh DU, Samant SD. Sulphamic Acid-An Efficient and Cost-Effective Solid Acid Catalyst for the Pechmann Reaction. Synlett. 2004;11:1909-1912.

29. Gu Y, Zhang J, Duan Z, et al. Pechmann Reaction in Non-Chloroaluminate Acidic Ionic Liquids under Solvent-Free Conditions. Adv Synth Catal. 2005;347(4):512-516.

30. Potdar MK, Rasalkar MS, Mohile SS, et al. Convenient and efficient protocols for coumarin synthesis via Pechmann condensation in neutral ionic liquids. J Mol Catal A: chemical. 2005;235(1-2):249-252.

31. De SK, Gibbs RA. An Efficient and Practical Procedure for the Synthesis of 4-Substituted Coumarins. Synthesis. 2005;8:1231-1233.

32. Rodríguez-Domínguez JC, Kirsch G. Zirconyl Chloride: A Useful Catalyst in the Pechmann Coumarin Synthesis. Synthesis. 2006;11:18951897.

33. Manhas MS, Ganguly SN, Mukherjee S, et al. Microwave initiated reactions: Pechmann coumarin synthesis, Biginelli reaction, and acylation. Tetra Lett. 2006;47(14):2423-2425.

34. Benelmekki M, Caparros C, Montras A, et al. Horizontal low gradient magnetophoresis behavior of iron oxide nanoclusters at the different steps of the synthesis route. J Nanopart Res. 2011;13(8):3199-3206.

35. Srivastava S, Awasthi R, Tripathi D, et al. Magnetic-nanoparticle-doped carbogenic nanocomposite: an effective magnetic resonance/fluorescence multimodal imaging probe. Small. 2012;8(7):1099-1109.

36. Yao Y, Miao S, Yu S, et al. Fabrication of Fe3O4/SiO2 core/shell nanoparticles attached to graphene oxide and its use as an adsorbent. $J$ Colloid Interface Sci. 2012;379(1):20-26.

37. Kangari S, Yavari I, Maasoumi B. Synthesis and heterogeneous catalytic activity of covalently immobilized hexamine cation as a magneticallyrecoverable nanocatalyst. Journal of the Iranian Chemical Society. 2015;12(10):1771-1779. 